\section{Pre-emptive resignation?}

THE Soviet Union last week resigned its membership of the World Psychiatric Association (WPA) because of Western pressure about the political misuse of psychiatry. The resignation was not entirely unexpected; Professor Marat Vartanyan, the Soviet representative on the WPA Ethics Committee, hinted last autumn that such a move was possible if Western national psychiatric associations continued with their plan to expel the Soviet All-Union Society of Neurologists and Psychiatrists (AUSNP) during the WPA General Assembly in Vienna next July.

At the previous WPA General Assembly (in Honolulu in 1977) a motion of censure against the Soviet Union was narrowly passed. Since then, several national psychiatric associations formerly opposed to sanctions against the Soviet Union have changed their attitudes, partly because of the further accumulation and dissemination of case histories by pressure groups such as the International Association on the Political Use of Psychiatry (IAPUP) but, according to Dr G. Bles, honorary secretary of IAPUP, chiefly because of the non-cooperative attitude of AUSNP.

The WPA General Assembly voted in 1977 to set up a special committee to monitor non-observance of the association's policy on the political use of refused to acknowledge the committee's existence. This flouting of a decision of the General Assembly, said Dr Bles, probably helped sway many national societies. be the case. psychiatry but AUSNP has consistently

By the end of last year, so many national societies had followed the initiative of the Royal College of Psychiatrists to expel AUSNF that the main problem in planning the agenda for Vienna was to decide which country should propose a motion to this effect. Now that the Soviet Union has offered what appears to be a pre-emptive resignation there seems little that the Western societies can do to bring pressure on their Soviet colleagues.

Sketchy details of two of the cases in which Soviet psychiatrists have allegedly confined dissident "patients" on political rather than medical grounds were provided to the WPA executive committee last year. So far, however, none of the Soviet evidence has been sufficient to allay Western fears, and attempts to arrange for psychiatrists from the West to visit alleged "prisoners of conscience" without unacceptable restrictions and conditions have met with no success. The official Soviet view, as propounded by $\mathrm{Dr}$ Aleksandr Snezhnevskii, is that all mental disturbance (including political dissent) is a type of schizophrenia.

The future WPA membership of other associations from the Soviet bloc remains in doubt. Further resignations, however, might be counter-productive. Although a few cases of the psychiatric confinement of dissidents have been reported in these countries they are, for the most part, isolated instances. A major walk-out would invite speculation that the practice is far more widespread than in fact appears to

Vera Rich

\section{Princeton bid to strengthen life sciences}

PrinCeton University, obviously stung by recent complaints of its own departments' low standing in the life sciences, has announced that it will establish a new programme in molecular biology and raise $\$ 46$ million to that end. Princeton has hired Arnold J. Levine and Thomas E. Shenk, both at the State University of New York, Stony Brook, as the first members of what could grow to be a 19-faculty department by 1989 . The university has also decided to raise \$29 million for a new building for the department to be set adjacent to the existing biological laboratory building.

Princeton as a whole ranked well in surveys of faculty quality made in 1969 and 1981 , the second of which was released a year ago. But the ratings show that its life sciences departments have constantly slipped.

In 1969 Princeton's biochemistry department was ranked sixteenth in the United States but only twenty-second in 1981. In 1969 its programme in cellular/ molecular biology ranked twelfth; in $\mathbf{1 9 8 1}$ it ranked twenty-eighth. University officials are alarmed by the contrast with other departments ranked in the survey. Of the 26 Princeton departments ranked in the 1969 survey, only three were not in the first 16 - but two of the three low-rankers were biochemistry and cellular/molecular biology.

Princeton's zoology was ranked fifth in 1969 and not ranked in the latest survey. Other areas of biology, where the university is strong, such as population biology and neurobiology, were not ranked. Chemistry held thirteenth place in both surveys, but a recent advisory council report on the department urged that it must take account of molecular biology in order to keep pace.

Robert May, the Class of 1877 Professor of Zoology at Princeton, says that the university had been planning to improve its life science departments gradually, until the advisory councils for chemistry, biology and biochemistry weighed in with the opinions that drastic action was needed to remedy the situation. Deborah Shapley
US criminology Chips has job,
agenda follows

\section{Washington}

IN a classic movie, actor Jimmy Stewart played a supposed bumpkin thrust into the Washington scene. Now, in real life, one James Stewart, who likes to be called "Chips", a former chief of detectives for the city of Oakland, California, has been appointed by President Reagan to head the National Institute of Justice - the Justice Department's research agency that hands out approximately $\$ 15$ million a year for social science research in criminology and related fields.

University social scientists are described as "outraged" by the appointment of "Chips", who impresses them as well intentioned but not knowledgeable about criminal justice research. The institute, formerly part of the Law Enforcement Assistance Administration (LEAA), became a separate agency when LEAA was dismantled in 1980 . Since its foundation in 1968 , it has come to be a useful source of funds for the social sciences, especially when the National Science Foundation's social science budget declined to $\$ 37$ million per year.

Social scientists are even more concerned about the 17 new appointees to the institute's advisory board. They include two present or former policemen, a security guard from Las Vegas, three judges, two lawyers, two state legislators, a politician who is running the transition team of the new governor of California, a hotel executive from Pennsylvania and an advertising executive for Procter and Gamble. There is one academic in the new group, a law professor at the University of South Carolina.

The board has met four times, in Washington DC, New Orleans, Memphis and Atlanta, but has not put forward a programme for the current fiscal year. The aim of these hearings is to listen to practitioners so that the institute's research can be made more useful. The board has also expressed an interest in passing on individual grant applications - something research agency advisory boards rarely do.

Recipients of the institute's funds have also discovered that since becoming acting director last August (he was confirmed in December), Stewart has passed very few grant applications, with the result that the institute is now behind in its programme for fiscal years 1982 and 1983 . The institute will, however, be able to spend the fiscal 1982 money once Stewart decides how it should be allocated.

In the movie, Jimmy Stewart triumphed in his Senate job and ended by doing a lot for the folks back home. Social science researchers, however, are still waiting to see what their James Stewart does for which of them.

Deborah Shapley 